Urbanismo 



\title{
Urbanismo e antiurbanismo no debate nacional
}

\author{
CANDIDO MALTA CAMPOS ${ }^{I}$
}

\section{Introdução}

A PRIMEIRA metade do século XX, no Brasil, foi marcada pela intensificação do debate social e cultural em torno da formação da nacionalidade, em que demandas emergentes pela modernidade conviviam com a evocação da essência nacional na busca de diretrizes ideológicas que pudessem orientar a construção da nação brasileira. Tais debates, contudo, embutiam termos contraditórios: enquanto a primeira referência tendia a apontar para as dimensões urbana e metropolitana do mundo moderno, a busca do caráter profundo da "brasilidade" quase sempre se voltava para a direção oposta - priorizando o mundo rural, a herança colonial e a suposta vocação agrária do país como marcos de nossa identidade.

No início do século, ao mesmo tempo que se acelerava o processo de urbanização, as cidades brasileiras se viam na contingência de assumir novos padrões de conformação e funcionamento, respondendo às necessidades geradas pela evolução econômica. A afirmação do país como nação exportadora de produtos agrícolas exigia novas configurações espaciais, intra- e interurbanas. Capitais, centros regionais e portos que protagonizavam o circuito agroexportador deveriam atender requisitos derivados da posição brasileira na divisão internacional do trabalho, e das relações sociais e econômicas internas associadas.

Nesse contexto ganhava corpo a introdução de instrumentais técnicos que pudessem articular a transformação de nossos centros decisórios, importadores e exportadores, com destaque para a modernização dos portos, a remodelação das áreas centrais, o saneamento e a criação de bairros residenciais destinados aos estratos dominantes. Entre os instrumentos arregimentados com esse objetivo emergia uma disciplina recém-instituída, Urbanismo. Formulações originalmente desenvolvidas para viabilizar a intervenção sobre a cidade moderna europeia, abalada pelo crescimento industrial, seriam seletivamente importadas e adaptadas por técnicos locais, visando atender nossos centros agroexportadores. Tal processo de transferência, porém, esbarrava em dilemas ideológicos, na medida em que a afirmação do urbanismo nos países centrais pressupunha um grau de industrialização e urbanização que não encontrava eco na situação local.

Consequentemente, a introdução do urbanismo como disciplina muitas vezes era acompanhada, no Brasil, pela discussão do urbanismo como princípio. Dessa maneira, além de sua acepção estrita como denominação da ciência e arte 
de construir e remodelar cidades - sentido consagrado pelos integrantes da Société Française des Urbanistes a partir da década de 1910 - o termo "urbanismo" também podia indicar uma postura ideológica que considerava como desejáveis e positivas a urbanização, a grande cidade e as formas de vida urbana em geral.

Nesse sentido, "urbanismo" se opunha a ruralismo, agrarismo e outras correntes de pensamento que viam com maus olhos as cidades. A oposição entre cidade e campo, como recurso poético ou fórmula retórica, era um tema recorrente na literatura e no pensamento ocidental desde a Antiguidade. Tradicionalmente - da Arcádia ao romantismo - as virtudes campestres eram contrapostas à perversões da vida urbana; por vezes, tendências opostas - do iluminismo ao progressismo do século XIX - realçavam as qualidades de civilização e cultura presentes na cidade, eventualmente condenando o "atraso" ignorante do mundo rural. ${ }^{1}$

No limiar do século XX a consagração da metrópole moderna como ápice da civilização, da Paris da Belle Époque aos arranha-céus nova-iorquinos, passando por Londres, Berlim e Viena, estabeleceu os modelos almejados pela nova vida urbana e metropolitana, em que a concentração populacional e econômica permitia padrões inéditos de consumo, estimulava a vida cultural e propiciava novas manifestações artísticas. O brilho dos grandes centros modernos, realçado pela remodelação urbanística, procurava ofuscar a crise da cidade industrial, cujas mazelas haviam inspirado reações de repulsa e movimentos reformistas, entre os quais compareciam as propostas científicas, artísticas e sociais do urbanismo.

Ecos desse triunfo alcançavam a América Latina e o Brasil, na medida em que nossas capitais intensificaram, a partir do final do século XIX, o processo de importação que buscava em fontes urbanas europeias novos padrões de consumo, estilos de vida e, por que não, modelos urbanísticos. Da reforma Passos no Rio de Janeiro à construção de Belo Horizonte, da transformação de Buenos Aires aos "melhoramentos" de São Paulo, Recife, Salvador, Belém, Santos etc., as capitais e portos protagonistas da economia agroexportadora adotavam, para pontuar seus espaços dominantes, elementos urbanos modernos, muitas vezes de tom parisiense: jardins, bulevares, arquitetura eclética, vitrines, monumentos.

A predominância ideológica do "urbanismo", contudo, esbarrava no caráter essencialmente agrário da estrutura econômica que amparava tais realizações. Nossa incipiente industrialização, embora já adquirisse peso econômico, permanecia à margem das políticas oficiais. Debates e propostas nacionais traíam a persistência, ao longo da primeira metade do século XX; de modelos, mentalidades e políticas agraristas.

De qualquer maneira, com a emergência de propostas articuladas nos meios culturais e técnicos no sentido de orientar o que se entendia como a construção da nação e da identidade brasileiras, a transformação e conformação do espaço urbano, elemento decisivo desse processo, tornava-se uma arena na qual 
repercutiam e se aprofundavam os debates em curso sobre o país e seu futuro (Ribeiro, 1996, p.53-65).

\section{Antiurbanismo, ruralismo e nacionalismo}

O problema da construção da nacionalidade ultrapassava os debates sociais e políticos: cultura e literatura tornavam-se campos de embate e proposição, inseridos na discussão sobre os rumos do país. Em relação ao dilema urbano/ rural, podemos entrever duas grandes referências no Brasil da época. A tônica liberal inerente à condição agroexportadora e sua emulação de modelos europeus remetia à valorização dos elementos da cultura urbana - legitimando, de um lado, as metrópoles europeias que comandavam o comércio internacional e, de outro, as capitais que comandavam localmente o processo de trocas.

Ao mesmo tempo, a base rural da economia apontava na direção oposta, destacando a importância do mundo agrário, tanto em suas tradições e estruturas seculares como em termos da modernização das técnicas de exploração e aparelhamento da terra. Surgiam então formas alternativas de legitimar a grande propriedade e a dominação oligárquica: pela continuidade harmônica em relação ao passado nacional, e pela introdução de avanços científicos e tecnológicos - engenharia agrícola, transporte ferroviário.

Com a intensificação do crescimento urbano no último quartel do século XIX, o quadro idílico pintado pela dominação patriarcal começou a ser rompido. Aos romantismo e indianismo do Império sucederia o realismo literário, revelando a crueza, o cinismo e o mal-estar das cidades. Onde antes pequenos núcleos urbanos mal sobreviviam em contraste com a opulência das fazendas, passávamos a ter cidades movimentadas e uma capital efervescente. A reação a esse avanço do "urbanismo", associado ao liberalismo e ao cosmopolitismo exacerbado pelo frenesi especulativo do Encilhamento - não tardou.

Na virada do século, a tônica do movimento de revalorização do Brasil passou a se concentrar na descoberta de um interior vasto e desconhecido. A terra e o homem do sertão tornam-se objeto de estudos e romances, do regionalismo literário: prefigurado por José de Alencar em Ogaúcho (1866) e O sertanejo (1875); e acentuado na década de 1890, com O sertão, de Coelho Neto, e Pelo sertão, de Afonso Arinos; aos estudos sobre folclore e cultura popular de Silvio Romero, culminando na obra de Euclides da Cunha (Os sertões, 1902), com sua denúncia do esquecimento a que o país relegava sua população interiorana, e do choque entre a "civilização" republicana e o "atraso" local.

Na visão de Euclides o contraste entre dois Brasis, um litorâneo e urbano, o outro sertanejo e rude, assume contornos trágicos. Do encontro entre ambos só poderia resultar incompreensão e violência, emblematizadas pela Campanha de Canudos. A “modernidade” importada pela República torna-se aparelhagem insana que, em vez de construir a nação, massacra aquele que poderia ter sido o povo brasileiro.

A equação funesta colocada por Euclides parecia condenar de antemão 
nossos esforços modernizadores, salientando a oposição irredutível entre o país urbano e seu interior esquecido. Como conciliar veleidades modernas com a dura, miserável realidade dos sertões? Não obstante, era indispensável encontrar um terreno comum sobre o qual construir a identidade nacional. Para isso seria preciso inverter os termos dessa proposição, transformando em virtude nossa herança rural, e denunciando como perigosas e exógenas as novidades citadinas. ${ }^{2}$

Proponentes dessa inversão ideológica já se destacam na virada do século XX. No mesmo ano da publicação de Os sertões, 1902, vem à luz Canã̃, obra mestra de Graça Aranha (1976), em que se vislumbram possibilidades de redenção no inculto universo sertanejo. A terra prometida estaria na exuberante natureza do interior brasileiro, a ser desbravada por imigrantes europeus. $\mathrm{O}$ labor honesto dos campos, porém, seria comprometido pela injustiça e corrupção das cidades, onde "o bafo dos traficantes tinha matado a poesia [e] levantado as tendas da especulação". Nas palavras do protagonista, "o trabalho digno do homem é a lavoura nos países novos e férteis como este" (Aranha, 1976, p.41-5).

A verdade estaria no campo, longe do artificialismo, dos modismos, dos vícios da cidade. No "debate diário da vida brasileira... Ser ou não ser uma nação" (ibidem, p.141), era comum condenar-se a suposta dissipação dos esforços de um "país essencialmente agrícola" em cidades parasitárias, falsos cenários de consumo urbano de costas para a "realidade nacional" dos sertões. Contrapunha-se um Brasil urbano, consumidor e cosmopolita ao país real, ou seja, o mundo rural, no qual estaria "o cerne da brasilidade [...] o tema da redenção do mundo rural permeava o projeto de um importante setor da intelectualidade brasileira" (Melo, 1998, p.261).

O processo de renovação ideológica e cultural se intensificou ao longo da década de 1910, particularmente por ocasião da Primeira Guerra, cujo abalo inspirou, no Brasil, movimentos de afirmação da nacionalidade. Reagindo contra a subserviente emulação cosmopolita dos primeiros anos do século, ${ }^{3}$ surgiram iniciativas como a Revista do Brasil (1916), a Liga Nacionalista (1917), campanhas pelo serviço militar obrigatório e pelo saneamento do país, visando redescobrir um Brasil esquecido nos ermos, campos e sertões.

Ganhavam repercussão, naquele momento, ideias patrióticas e/ou ruralistas. Enquanto o nacionalismo progressista de Monteiro Lobato, embora pretendesse reverter o atraso rural, voltava-se para o modelo empreendedor norte-americano, pensadores como Alberto Torres eram mais conservadores, condenando o desvirtuamento da nacionalidade brasileira nas grandes cidades e propunha o retorno ao campo e aos valores da terra como caminho para a afirmação do país. Nos livros $O$ problema nacional brasileiro e $A$ organização nacional, publicados em 1914, Torres lançou um projeto para a construção da nação brasileira, tema que seria retomado inúmeras vezes nas décadas seguintes. ${ }^{4}$ Acreditava num Estado centralizado, forte e corporativo, opondo-se ao liberalismo que marcava nossa cultura urbana. O Brasil teria vocação agrária: "A terra é a 
base da riqueza, tudo o mais é diversionismo perigoso". Entretanto, condenava a dependência em relação à agricultura de exportação, propondo incrementar a policultura destinada ao mercado interno (Iglesias, 1978, p.29).

Tal postura ideológica resolvia de uma só tacada as duas grandes fraturas que ameaçavam a República Velha: a falta de legitimidade das estruturas políticas e a emergência dos conflitos sociais urbanos, que vieram à tona explosivamente com as greves de 1917-1918. As primeiras podiam ser condenadas como espúria politicagem descolada da realidade nacional; os últimos podiam ser reduzidos a produtos de influências exógenas, artificialmente disseminadas em nossas cidades. A volta a uma suposta "essência" brasileira localizada no mundo rural permitiria resolver ambas as questões: a primeira, pela retomada da tradição patriarcal, paternalista e autoritária; a segunda, pela negação do mundo urbano moderno e seus elementos incômodos, como a produção industrial e a população operária.

Os temas do nacionalismo e da nacionalidade, combinados à defesa do autoritarismo e da centralização, seriam explorados em seguida por outro autor influente, Oliveira Vianna. Tendo alcançado notoriedade imediata com Рориlações meridionais do Brasil, ensaio sociológico publicado em 1920, lançou em 1923 Evolução do povo brasileiro, obra antropológica, e, em 1927, O idealismo da Constituição, crítica à estrutura política liberal da República Velha.

Assim como Alberto Torres, Oliveira Vianna era ruralista, identificando na unidade produtiva agrária - a fazenda - a célula da formação social brasileira, e no clã rural a base de sua cultura política. As relações capitalistas e o industrialismo seriam ocorrências excepcionais e minoritárias no Brasil, limitadas a alguns centros, tais como São Paulo. Para orientar a construção da nacionalidade e do Estado brasileiros, propunha recuperar os valores do patriarcado rural, comprometido com a terra e seu povo, em contraposição à alienação das elites urbanas. Apoiado nessa visão quase idílica do campo, considerava o ruralismo "traço dominante e permanente na formação do povo brasileiro" (Doria, 1993, p.236; Paim, 1993, p.297-310).

Embora tenham sido marcados por crises políticas, os anos 1920 foram um período áureo para a economia cafeeira de exportação. O sucesso dos sucessivos esquemas de valorização do café - o Convênio de Taubaté, em 1906, a "segunda valorização", de 1917, e a terceira, de 1921 - culminaria no Plano de Defesa Permanente do Café, instituído em 1924 (Saretta, 1997, p.218). No governo Arthur Bernardes, o líder ruralista Rafael Sampaio Vidal, representante da cafeicultura paulista, foi nomeado ministro da Fazenda. Para presidir o Banco do Brasil, foi escolhido Cincinato Braga, teórico da modernização de base agrária.

Suas ideias foram expressas em Brasil novo (1930-1931) e Magnos problemas econômicos de São Paulo (1921), que defendiam uma nova civilização agrícola para o Brasil, baseada na diversificação, modernização e racionaliza- 
ção da atividade agroexportadora: "Montemos no Brasil uma nova civilização pastoril e agrária, não a de nossos atrasados antepassados, mas uma moderna, iluminada pela ciência". Braga condenava ainda as "indústrias artificiais" e o "protecionismo manufatureiro". Crítico da urbanização intensiva, denunciava o "artificialismo e parasitismo" das cidades, vistas como centros de consumo, em contraste com o "ambiente saudável" e produtivo do campo (Saliba, 1981, p.IX, 136-45).

\section{Modernismo e urbanidade}

A despeito de sua influência, é inegável que a ascensão da ideologia antiurbana entre nossos pensadores oficiais contrastava com a aceleração, no primeiro pós-guerra, da incorporação de modernos modos de vida às concepções dominantes da existência nas grandes cidades brasileiras. Nicolau Sevcenko (1992; 1997a, p.106-27; 1997b) descreve tal processo como uma intensificação de ritmos, um crescendo de novidades, uma adesão entusiástica aos tempos modernos, permeada pelas contradições inerentes ao "atraso" percebido na cidade, em contraste com suas aspirações.

Em seu primeiro momento, o movimento modernista brasileiro se identificou com a inovação cultural das vanguardas europeias, e trouxe implícito o reconhecimento da validade e inexorabilidade de aspectos da modernidade urbana. No entanto, o modernismo sucumbiria em breve a tendências regionalistas e à ânsia de redescobrir um Brasil interiorano e "autêntico". Ao clamor urbano de Klaxon (primeira revista modernista, de 1922) sucederia o retorno a Terra Roxa e Outras Terras (periódico lançado em 1925). Na trajetória de Mário de Andrade em suas viagens de redescoberta do Brasil (cidades históricas de Minas Gerais, 1924; Nordeste e Amazônia, 1927, 1936), transparece a direção eleita na busca da essência nacional entre os modernistas.

Podemos entrever nesse movimento a insatisfação da geração de 1920 com as cidades então existentes no Brasil. O tom áulico (na empolada arquitetura eclética) e o ambiente repousante (nos bairros refinados da elite) buscado pelos construtores da capital agroexportadora não se adequavam ao frenesi modernista. Se o desejo de transformação que começava a ser assumido como lema contrastava com paisagens urbanas que emulavam execrados padrões burgueses europeus, o falso bucolismo dos jardins à europeia desmentia a intensa realidade tropical. $^{5}$

A sensibilidade modernista traduz a exasperação inspirada por tal contraste. $\mathrm{O}$ afã por uma cultura cosmopolita se esboroando na pequenez do mundinho paulistano ecoa na Pauliceia desvairada de Mário de Andrade; episódios pitorescos ou patéticos traduzem a fragmentação social trazida pela imigração na obra de António de Alcântara Machado. No Rio, o sucesso dos romances de Benjamin Costallat evidencia a sede por atributos citadinos e atualizados da vida moderna.

Avultava, nesse quadro paradoxal, a questão das transformações urbanísti- 
cas, equipamentos e estruturas urbanas. Esses se encontravam em descompasso com as veleidades inovadoras assumidas como motes dos novos modelos de vida e comportamento. Mesmo fora dos círculos modernistas, o fascínio do automóvel ganhava força, e, ao mesmo tempo em que a circulação cada vez mais intensa exigia novos patamares de intervenção em termos de infraestrutura viária, a verticalização entrava na pauta das transformações urbanas, elegendo o arranha-céu como novo símbolo da cidade, levando à ruptura das volumetrias parisienses.

Alguns modernistas chegaram a abdicar da perspectiva predominante, dividida entre a imensidão brasileira e as vanguardas europeias, e dirigiram seu olhar à questão urbana local. Em 1925, a ala mineira do modernismo literário lançou em Belo Horizonte sua publicação A Revista, na qual Magalhães Drummond (1925) procurou definir o "momento brasileiro" - etapa decisiva pela qual estaria passando o país, em busca da identidade brasileira e diretrizes que poderiam orientar a evolução de nossa cultura e sociedade. "Momento historico" para "constituir uma nacionalidade", no qual deveriam ser construídos um ideal, um espírito e um pensamento brasileiros. Ganhava corpo então o magno problema da "organisação do Brasil para durar como Estado e como nacionalidade" (Drummond, 1925, n.2, p.44-6).

Tal problema, com o país ainda marcado pelos valores tradicionais associados à vida rural, e voltado às atividades agrícolas, passaria necessariamente pela questão urbana. Segundo o autor, o "criterio brasileiro" que presidiria à construção nacional deveria superar "innumeros preconceitos $[\ldots]$ instransponiveis obstaculos ao nosso natural evolver". O primeiro deles seria a falsa noção de que estaria "no 'urbanismo' a causa principal de nossos males economicos" (ibidem, p.32).

Mais que a ciência da urbanização, "urbanismo" implicava a predominância dos valores urbanos sobre os rurais. Em termos econômicos, significava contestar o predomínio da produção agrária; no panorama cultural, corresponderia a veicular a civilização dos centros adiantados. Nesse sentido o Brasil padeceria, não por excesso de cultura urbana, mas por "carencia de urbanismo" (ibidem).

Ao mesmo tempo, o autor não deixava de ligar o termo à construção e remodelação de cidades. A despeito da presença de pensadores "antiurbanistas", os brasileiros estariam se esforçando para alastrar a civilização por meio de um "trabalho de urbanisação" (com a fundação planejada de novas cidades) e de uma "politica de urbanisação" (tendo como exemplo Belo Horizonte) (ibidem, p.33).

Combatendo a persistência de uma "these antiurbanista", Magalhães Drummond revelava rara percepção dos rumos que tomariam as transformações sinalizadas no "momento brasileiro" da primeira metade do século (ibidem, p.32). Além disso, apontava para o peso assumido, no âmbito das construções ideológicas dominantes no Brasil, por tal preconceito contra o urbanismo - a ideia de que seria equivocada e inviável para o país uma orientação que o levasse 
a assumir como prioritários a via do desenvolvimento urbano e os valores da civilização industrial.

Modernistas e urbanistas, porém, não partilhavam necessariamente as mesmas plataformas ideológicas. Nos anos seguintes, o movimento Verde-Amarelo voltaria a associar a procura da brasilidade aos elementos que pautavam o nacionalismo de Alberto Torres: a autoridade, a tradição, o mundo rural. ${ }^{7}$

Enquanto isso os ventos revolucionários do tenentismo e da oposição à República Velha acirravam o dilema brasileiro. Ao final dos anos 1920, o governo aproximava-se dos industrialistas (autonomizados naquele momento pela criação da Federação da Indústria do Estado de São Paulo (Fiesp) e patrocinava a elaboração de grandes planos urbanísticos, como o Plano de Avenidas de Prestes Maia, em São Paulo, e o Plano Agache, no Rio. Enquanto isso, urbanismo e industrialismo não faziam parte do programa revolucionário. Em termos econômicos, o liberalismo que marcava o ideário da Aliança Liberal, coalizão que apoiou Getulio em 1930, costumava se expressar pelo laissez-faire; no Brasil a ideologia livre-cambista casava-se com a ideia da "nação essencialmente agrícola". Para os aliancistas "a indústria era vista como atividade artificial" pois implicava "a emergência de conflitos e lutas que não cabiam numa nação como o Brasil”. A volta ao campo e às "verdadeiras tradições brasileiras" seria a solução para evitar a luta de classes, mal maior do industrialismo moderno (Decca, 1981, p.166-7).

\section{Engenheiros, arquitetos e o debate nacional}

O manifesto da poesia Pau-Brasil, em 1924, exigia, para renovar o país, engenheiros no lugar de advogados, denunciando o bacharelismo que representava, na época, o caráter artificial de nossas instituições e elites urbanas (Andrade, 1924). ${ }^{8}$ Embora a perspectiva modernista encaminhasse esses engenheiros para a construção ex novo da nação, de preferência tomando como base o terreno virgem do trópico, e não a realidade contraditória das cidades, o papel dos técnicos responsáveis pela construção do ambiente material passava a ser decisivo no processo de transformação do país e de seus centros urbanos - inserindo-os, inevitavelmente, no debate nacional brasileiro.

Entre arquitetos, engenheiros e engenheiros-arquitetos, o entreguerras foi pautado por acontecimentos marcantes - em que compareciam, nas discussões profissionais, estéticas e sociais, aspectos do confronto ideológico em torno da construção da identidade local e da nação brasileira. O primeiro Congresso Pan-Americano de Arquitetos, em Montevidéu (1920), suscitou a organização da categoria no Rio de Janeiro, com a fundação do Instituto Brasileiro de Architectos e da Sociedade Brasileira de Architectos, fundidas em 1924. As diretrizes defendidas para a inserção de "engenheiros, architectos e constructores" no projeto de construção do país envolviam nada menos que "estimular e orientar as boas iniciativas para a remodelação de nossas cidades, o desenvolvimento de nossa viação, a cultura racional dos nossos campos e a intensificação das nossas industrias - eis o nosso programma". ${ }^{9}$ 
Um tema revelador das alternativas ideológicas colocadas em face dos técnicos brasileiros referia-se à eleição do estilo arquitetônico nacional. As duas tendências presentes na Exposição do Centenário, em 1922, predominariam até os anos 1930: de um lado, o ecletismo Beaux-Arts, que marcava o ensino na Escola Nacional de Belas-Artes e nas paulistas Escola Politécnica e Escola de Engenharia Mackenzie; de outro, o emergente movimento neocolonial, contando com a militância de José Mariano, no Rio, e de Ricardo Severo, em São Paulo. Naquele momento, eventuais ecos do Movimento Moderno - o chamado "futurismo" arquitetônico - ainda eram vistos, ora como curiosidade, ora como exotismo condenável.

Impossível não ver a correspondência entre tais opções estilísticas e as concepções então em pauta em termos da identidade do país e do papel de suas cidades. Linguagem oficial da primeira República, o ecletismo exprimia a cultura cosmopolita e liberal do setor agroexportador, para o qual a emulação dos centros europeus que presidiam a hierarquia comercial e financeira constituía indispensável recurso legitimador. Ligava-se, portanto, à primazia das cidades enquanto centros decisórios, importadores e exportadores, e estava sujeito à mesma crítica antiurbana que condenava o artificialismo, o parasitismo e o estrangeirismo de nossas capitais. ${ }^{10}$

Enquanto a afetação de estilos históricos importados, em bulevares à parisiense, configurava paisagens urbanas pouco aptas a sediar a ansiada brasilidade, $\mathrm{o}$ movimento pela retomada do estilo colonial apontava na direção oposta à das metrópoles europeias que inspiravam nossas reformas urbanísticas. A linguagem neocolonial denotava nostalgia por um mundo anterior à indústria e à metropolização, um ideal histórico supostamente harmônico, em que a arquitetura se adequaria à paisagem natural e social. Seus modelos eram a grande casa rural, o convento e a igreja, marcos de uma sociedade tradicional e agrária. Ressonâncias patriarcais que não deixavam de agradar às elites agroexportadoras: lembremos que a campanha pelo neocolonial coincidiu com a emergência do nacionalismo autoritário e conservador de Alberto Torres e Oliveira Vianna nos anos 1910 e 1920.

Liberalismo e autoritarismo, cosmopolitismo e nacionalismo eram os polos entre os quais se debatiam nossos ideólogos, e o debate arquitetônico e urbanístico não podia se furtar a tais questões. A mesma polêmica acirrada, o mesmo dilema insolúvel atormentava engenheiros e arquitetos. No III Congresso Pan-Americano de Arquitetos em Buenos Aires, de 1927, a dúvida sobre qual seria a "orientação espiritual da arquitetura na América" permaneceu sem resposta: "as diversas tendencias artisticas que luctam actualmente por soluções adequadas para os problemas que se apresentam às construcções modernas, são igualmente interessantes". Todos os estilos em disputa poderiam oferecer contribuições adequadas, conforme o caso. Mas no que diz respeito à premiação, o encontro de Buenos Aires consagrou o ecletismo Beaux-Arts: os prêmios de honra referentes ao Brasil foram para Ramos de Azevedo e Christiano das Neves. ${ }^{11}$ 
Três anos depois, o IV Congresso realizou-se no Rio de Janeiro, e a corrente neocolonial prevaleceu. Entre os temas a serem discutidos no encontro destacava-se a questão do estilo ou "orientação espiritual da architectura" a ser adotada num continente dividido entre "regionalismo e internacionalismo". Influenciadas por José Mariano, as conclusões recomendavam "o estudo e a pratica da Architectura de caracter nacional", e "o sentido da tradição ornamental regional", advogando que "não existe incompatibilidade entre o regionalismo e o tradicionalismo com o espirito moderno". ${ }^{12}$

No que se refere ao urbanismo, as conclusões dos congressos foram semelhantes, marcadas pela desconfiança em relação ao crescimento metropolitano do Hemisfério Norte. Em Buenos Aires, condenou-se a "densidade exagerada de edificação", ou seja, a verticalização excessiva. No Rio de Janeiro, reafirmou-se a necessidade dos "planos geraes", mas o uso de consultorias estrangeiras deveria ser reduzido ao mínimo. Entre os maiores problemas identificados nas cidades do continente estaria a expansão urbana horizontal (loteamentos) e vertical (arranha-céus) que se propunha regulamentar por meio de legislação específica. ${ }^{13}$

Em maio de 1931, a Divisão de Arquitetura do Instituto de Engenharia de São Paulo, presidida por Alexandre de Albuquerque e apoiada pelo então prefeito Anhaia Mello, promoveu um Congresso de Habitação para discutir as tendências da construção moderna e suas aplicações sociais. ${ }^{14} \mathrm{~A}$ tônica das comunicações sobre esse assunto foi a defesa da moradia individual, preferencialmente situada em cidades-jardim, como modelo para a habitação popular no Brasil: "Da vida promiscua em cortiços sahe um corso de pervertidos, de delinquentes, cortejado por molestias terriveis. A casa individual, rodeada de ar e de luz [...] é a cellula mater das raças fortes". Prédios de apartamentos eram condenados. ${ }^{15}$

A nova cidade brasileira, portanto, devia abdicar de traços metropolitanos como altas densidades e habitações coletivas, aproximando-se de um ideal campestre. Chegou-se a defender o padrão das casas rurais brasileiras, simples e rústicas, como inspiração para a arquitetura das novas moradias populares. $\mathrm{O}$ estilo arquitetônico preferido no Congresso de Habitação - que teve como convidado especial José Mariano - seria o neocolonial cujo espírito se adequaria aos modelos individuais e rurais propostos no congresso para a habitação urbana.

No campo urbanístico, a orientação neocolonial que prevaleceu no Congresso da Habitação e no IV Congresso Pan-Americano de Arquitetos, associada à redenção dos conflitos urbanos por meio de valores tradicionais e rurais, era ecoada por uma visão reguladora que, a exemplo do movimento pelas cidades-jardim, pretendia garantir as qualidades do campo no âmbito da vida urbana. Para isso era preciso controlar as densidades e estabelecer padrões de extensão urbana amparados no modelo dos bairros-jardim. ${ }^{16}$

Tais posições ganhariam peso nos anos 1930, ao mesmo tempo que se acentuavam o processo de urbanização, a industrialização e a entrada em cena 
das massas urbanas. E, a partir de meados da década, a ascensão autoritária voltaria a destacar posições "antiurbanistas" no debate nacional brasileiro.

\section{Ascensão autoritária e volta ao campo}

As ideologias autoritárias e nacionalistas emergentes nos anos 1930, com suas conotações conservadoras e seu débito em relação ao pensamento de Alberto Torres e Oliveira Vianna, não priorizavam necessariamente a transformação urbanística e a metropolização como objetivos do novo Brasil.

$\mathrm{Na}$ óptica do pensamento antiliberal dos anos 1930, os grandes centros urbanos eram vistos com desconfiança, associados à penetração de ideologias estrangeiras, do perigo bolchevique e dos enganos do liberalismo. Valores autenticamente brasileiros deveriam ser buscados nos campos, onde os elementos conservadores da terra, da pátria e da família se combinavam ao potencial representado por imensos espaços abertos à construção da nacionalidade. A moderna nação brasileira seria realizada em consonância com suas mais profundas tradições - evitando abalos e conflitos sociais presentes na grande cidade.

Naquele momento, vinham à luz duas obras seminais sugerindo diretrizes para a formação da identidade nacional, desenvolvendo os temas lançados pela geração anterior. Raizes do Brasil (1936) propõe a adoção efetiva do modelo liberal-democrático como caminho para a "nossa revolução" e salienta o papel positivo do processo de urbanização na transformação do país, a obra de Gilberto Freyre adota uma óptica oposta e elege o mundo rural, patriarcal e agrário como paradigma da brasilidade. Vistas sob o prisma da decadência da sociedade tradicional, as cidades trariam a degradação "pela liberdade e pelas condições de vida [supostamente inferiores] do meio urbano" (Freyre, 1961, p.179). ${ }^{17}$ Nos anos seguintes, a oficialização de Freyre como grande formulador da identidade brasileira consagraria tais ressonâncias antiurbanas.

A questão urbana encontra-se sistematicamente ausente de obras como Diretrizes do Estado Novo e As ideias do Presidente Getulio Vargas, ou da publicação preparada por Gustavo Capanema no Ministério da Educação e Saúde, em que predomina a visão do Brasil como país essencialmente rural. Segundo o texto do Ministério da Educação e Saúde (MES): "Não cabe aos centros urbanos o papel principal na vida do país. Ao contrário, os campos representam a parte essencial" (Galvão, 1942; Gentil, 1939). ${ }^{18}$

Tal visão se consubstanciaria na campanha da "marcha para Oeste", reclamando para o progresso os sertões brasileiros. O país deveria voltar-se para o interior, integrando o território no organismo coeso do Brasil Novo. A concepção de Goiânia, a partir de 1933, simbolizaria essa tendência: aproveitando as lições do urbanismo moderno, seria criada no planalto central uma cidade harmoniosa, em equilíbrio com a natureza, para sediar o esforço de conquista da fronteira Oeste. O plano original da cidade foi traçado por Attílio Corrêa Lima; a encomenda destacava a necessidade de um zoneamento de funções, um sistema de parques e jardins, e um centro cívico. No plano, receberam destaque os 
parques, park-ways, jardins, praças, vias arborizadas e canteiros (Maciel, 1996, p.640-3). As largas avenidas propostas por Corrêa Lima favoreciam o caráter monumental a ser assumido por Goiânia, ao mesmo tempo que permitiam uma ocupação pouco densa e imersa no verde.

Com a contratação de Armando de Godoy para rever o plano, em 1935, a nova orientação urbanística adotada salientou ainda mais a integração com o verde, abandonando o geometrismo monumental. O setor Sul da cidade foi retraçado na forma de moderno subúrbio-jardim, inspirado no plano de Radburn, com ruas em cul-de-sac, vias de pedestres, espaços livres e de recreação, segregação dos usos comerciais, sugerindo um espaço sem os conflitos e mazelas da grande cidade. ${ }^{19}$

Godoy pretendia limitar, de um lado, a expansão do centro comercial, impedindo sua ampliação sobre os bairros circundantes; e, de outro, a expansão da própria cidade, que não deveria ultrapassar os 50 mil habitantes e seria circunscrita por um cinturão verde, agrícola e recreativo. Qualquer crescimento urbano suplementar deveria ocorrer de forma descentralizada: "o perimetro urbano ficará fixado para sempre $[\ldots]$ as zonas de extensão [...] não existirão. A cidade teria, assim, garantida em sua circunvizinhança, uma faixa de vegetação $[\ldots] \mathrm{o}$ excesso de população, ou seja, a extensão da cidade, se fará em novos núcleos suburbanos que foram designados 'cidades-satelites'". ${ }^{20}$

Os amplos espaços verdes e perspectivas horizontais do plano de Goiânia ecoariam a vastidão do planalto, enquanto suas baixas densidades, bairros-jardim e cidades-satélite consubstanciariam uma ocupação sem conflitos, evitando os males do crescimento urbano "excessivo" e "desordenado". ${ }^{21}$

Dessa maneira, a orientação adotada em Goiânia tendia a privilegiar propostas reguladoras e visões harmônicas da cidade, derivadas da crítica às grandes metrópoles. Suas diretrizes de suburbanização, recreação e limitação do crescimento, inspiradas no movimento pelas cidades-jardim, pretendiam conciliar cidade e campo em unidades limitadas. Enquanto essa tônica comparecia em um ideário urbanístico eminentemente moderno, as qualidades áulicas exigidas pelo autoritarismo eram fornecidas por modelos urbanísticos mais grandiosos, que iriam transparecer a partir de 1937, no regime ditatorial do Estado Novo.

Se, de um lado, a ideologia dominante via com desconfiança o potencial "desagregador" e as contradições e disputas evidenciadas nas grandes cidades, o processo de centralização política que caracterizava o regime varguista exigia o privilegiamento das capitais. A solução para tal impasse seria fornecida pelo urbanismo monumental. Exacerbadas pelo Estado Novo, as concepções urbanísticas daquele momento iriam adotar o lema da monumentalidade estatal como imagem que conciliaria o crescimento urbano com os valores de um país agrário: a coesão e a autoridade, firmemente plantadas no solo. ${ }^{22}$

Arranjos axiais e composições simétricas seriam empregados para criar uma visão urbana adequada à concepção corporativa de sociedade inerente ao regime 
autoritário. Na remodelação da capital federal pelo prefeito Henrique Dodsworth e seu secretário de Viação e Obras, Edison Passos - Esplanada do Castelo, Avenida Presidente Vargas, Ministérios da Fazenda, do Trabalho e da Guerra -, composições monumentais, clássicas mas "racionalizadas" exprimiam intenções modernizadoras que não abalavam as tradicionais estruturas de dominação.

Grande exceção nesse panorama, o edifício do MES projetado pela equipe de Lucio Costa trazia a linguagem arquitetônica da era industrial: funcionalidade, depuração, modulação, clareza, brilhantemente reinterpretadas para a situação brasileira. Contudo, a implantação revolucionária do edifício destoava dos quarteirões compactos do Castelo, conformando um fragmento de cidade modernista em meio ao peso dos blocos institucionais e comerciais da capital. Dentro do ministério, a incongruência entre os pressupostos industrialistas do Movimento Moderno e a ideologia dominante no momento comparece no mural de Portinari que adorna a Sala de Despachos: pretendendo retratar a economia brasileira, a obra se compõe de cenas alusivas à agricultura (café, algodão, mate, cacau) extração, pecuária. A indústria está ausente, e única referência ao mundo urbano é uma solitária cena representando a construção civil.

Com o eventual incentivo varguista à industrialização e a criação da Companhia Siderúrgica Nacional, a partir de 1941, veio novamente à baila o tema do urbanismo. A desconfiança em relação aos grandes centros urbanos, por parte da ideologia estado-novista, concorreu na opção pela implantação de uma cidade industrial exemplar, longe das metrópoles, contando com cuidadoso projeto urbanístico. Confiado a Attílio Corrêa Lima, o plano de Volta Redonda se inspirou nos princípios do urbanismo moderno, adaptados às limitações ideológicas do regime. Instalações fabris, centro comercial, centro institucional e bairros residenciais foram separados por rigoroso zoneamento. Tendo a indústria como elemento central, Volta Redonda ecoa dispositivos espaciais de controle adotados nas vilas fabris do início do século (Silva et al., 1996, p.149-50).

Outra diretriz conservadora adotada em Volta Redonda foi a preferência pelas moradias individuais. Embora Corrêa Lima - já afinado com princípios do Movimento Moderno - advogasse o emprego de habitações coletivas, a direção da Companhia Siderúrgica Nacional (CSN) considerava casas isoladas mais consoantes com as tradições brasileiras, resguardando os valores familiares e garantindo relações espaciais mais próximas da vida no campo. Lima acabaria chegando a uma solução de compromisso, em que predominavam casas geminadas, com alguns prédios de apartamentos destinados a operários solteiros (ibidem, p.151-60).

Como sempre, tais implicações ideológicas ecoavam o debate mais amplo em torno da modernização brasileira, no qual se enfrentavam, naquele momento, as teses industrialistas e intervencionistas de Roberto Simonsen, de um lado, e o liberalismo e agrarismo de Eugênio Gudin, de outro - embate que culminou, dentro do governo federal, na controvérsia econômica de 1944 e na Conferência de Teresópolis. O resultado desse confronto não foi conclusivo, 
porém, e os dilemas sobre a orientação a ser adotada pelo país iriam prosseguir nas décadas seguintes.

\section{Considerações finais}

A intenção de construir uma nacionalidade, uma nação, o Brasil, perspectiva que atravessava os campos artístico e cultural, também marcava a vontade modernizadora dirigida à construção física do aparato da modernidade sobre o território nacional - a edificação propriamente dita, suas infraestruturas, suas cidades. Posicionar-se nesse debate significaria, portanto, encarar a questão do papel a ser exercido, no país que se pretendia construir, pelo processo de urbanização, pela cultura urbana, e, por que não, pelo urbanismo.

De maneira geral, as posições ideológicas em pauta na época debatiam-se entre termos contraditórios: de um lado, a aspiração do moderno, com suas referências urbanas, europeias e norte-americanas; de outro, a busca do caráter nacional brasileiro, em que predominariam elementos tradicionais e rurais. $\mathrm{Ru}-$ ralismo e antiurbanismo são posturas ilustrativas de tais dilemas, evidenciando limites ideológicos presentes no momento da introdução do urbanismo no Brasil.

O ideário liberal associado à economia cafeeira, emulando modelos europeus e valorizando atributos urbanos e cosmopolitas, tendia a exaltar as metrópoles europeias que comandavam a divisão internacional do trabalho. Para legitimar as capitais nacionais e regionais que representavam localmente essa hierarquia comercial, os elementos da vida urbana moderna tornavam-se referências desejáveis. Todavia, no que se refere às transformações urbanísticas o intervencionismo indispensável à criação de quadros urbanos à europeia esbarrava no liberalismo inerente à condição agroexportadora, comprometendo o processo de introdução do urbanismo moderno entre nós.

Disciplina nascida sob a égide da reforma da cidade industrial, a ciência urbanística não estava totalmente à vontade no modelo agroexportador. Suas propostas reguladoras eram barradas pelo liberalismo e comercialismo de nossos centros urbanos. Sua incorporação aos projetos reformistas locais também era problemática, na medida em que a maioria de nossas propostas modernizadoras não trazia um componente industrialista, e todas relutavam em admitir a possibilidade de uma ruptura com as estruturas existentes - tornada ainda mais difícil pela inserção do país como elo dependente e subordinado no circuito internacional de trocas e nos esquemas de poder a esse associados.

Consequentemente, nossas cidades tendiam a ser vistas como centros decisórios, residenciais, comerciais e de consumo, abstraindo-se a presença da produção industrial e da população trabalhadora. Muitos projetos modernizadores nem concebiam a presença do operariado como elemento integrante da vida brasileira, pretendendo resolver os conflitos sociais urbanos por meio da volta ao campo. Dentre a grande diversidade de visões e projetos disputando espaço no debate nacional, mesmo aqueles em que desponta a abordagem de questões sociais, parece ser um ponto comum o pouco apreço pelas cidades. 
O retorno ao mundo rural e agrário era uma visão tentadora, na medida em que se propunha a exorcizar os grandes fantasmas dos setores dominantes brasileiros. Se o ideário liberal-democrático - tão urbano e importado como as demais inovações citadinas - corria o risco de deixar de ser mera fachada e passar a questionar a dominação oligárquica, essa poderia ser legitimada pela retomada de tradições patriarcais e autoritárias identificadas no Brasil profundo. Os conflitos sociais emergentes na cidade poderiam ser minimizados por meio da negação do mundo urbano e particularmente de seus componentes mais ameaçadores, como a urbanização acelerada, a indústria e os contingentes operários.

Revistos hoje, após décadas de um intenso processo de urbanização que alterou radicalmente a face e as referências do país, os termos conservadores, a tônica ruralista e a nostalgia do campo presentes em correntes do pensamento brasileiro na primeira metade do século parecem se situar na contramão da história. Não obstante, deixaram marcas profundas no processo de construção da nacionalidade e da identidade brasileiras, no qual a incorporação de valores urbanos modernos - como a impessoalidade, a participação política e o respeito a normas abstratas - tende a ser problemática. Se o "urbanismo" como tendência prevaleceu, o urbanismo propriamente dito ainda não ganhou cidadania plena no Brasil.

\section{Notas}

1 Duas obras clássicas resumem a evolução de ideias favoráveis ou críticas em relação às cidades no pensamento ocidental: $O$ campo e a cidade na história e na literatura (Williams, 1989, publicado originalmente em 1973) e o ensaio "A cidade segundo o pensamento europeu - de Voltaire a Spengler" (Schorske, 1989, p.47-57).

2 Quase todos os nacionalismos do século XIX partilham postura semelhante. Para citar apenas um exemplo mais próximo, em $A$ cidade e as serras Eça de Queiroz explora o mesmo contraste entre a metrópole opulenta mas pervertida e a pureza revigorante do mundo rural: seu Jacinto de Tormes - parcialmente inspirado em Eduardo Prado, literato paulista radicado em Paris - exemplo de dândi metropolitano e mondain, é redimido pela volta ao bucolismo do mundo rural português.

3 Representantes de nosso cosmopolitismo liberal, de olhos vidrados na Europa, pouco atentavam para a realidade local. Um bom exemplo é o diplomata Oliveira Lima (2000) em sua Formação histórica da nacionalidade brasileira.

4 Podemos citar Monteiro Lobato (Ideias de Jeca Tatu, 1918); Júlio de Mesquita Filho (A crise nacional, 1925); Pandiá Calógeras (A união brasileira, 1927 e Problemas de governo, 1928); Cincinato Braga (Brasil novo, 1931); Menotti del Picchia (Soluções nacionais, 1931); Cândido Motta Filho (Alberto Torres e o tema da nossa geração, 1931); Miguel Reale (O Estado moderno, 1934); Azevedo Amaral (O Estado autoritário e a realidade nacional, 1938); e Francisco Campos (O Estado nacional, 1939), entre outros.

5 Como descreve um contemporâneo, "a capital de São Paulo, espelho da vida do estado modelo, com a sua area bem dividida, a sua construcção imponente, estendida do centro movimentado à doçura dos bairros" (Illustração Brasileira, v.X, n.19, s.n.p., março 1922). 
6 O autor cita os resultados do censo de 1920, que havia revelado a avassaladora predominância da população rural sobre a urbana.

7 São as mesmas ressonâncias conservadoras assumidas pelo fascismo italiano e pelo nazismo, em sua ideologia antiurbana - a despeito de sua adoção da técnica industrial e da política de massas. Segundo Gramsci (1978, p.317), no dilema entre ruralismo e "urbanismo" que marcava o pensamento fascista, a primeira tendência havia levado a melhor: "Na Itália, verificou-se um início de fanfarra fordista (exaltação da grande cidade, planos reguladores para a grande Milão, etc.), depois verificou-se a conversão ao ruralismo [...] a exaltação do artesanato e do patriarcalismo idílico [e] uma luta contra a propriedade industrial".

8 Em 1928, Oswald ousaria uma síntese entre as perspectivas metropolitana e nativista do modernismo: o movimento antropofágico - propondo, pela incorporação violenta, a fusão cultural entre avanços europeus e espontaneidade tropical. No entanto, tais formulações iriam ter continuidade apenas quarenta anos depois, com as vanguardas neoconcretista e tropicalista dos anos 1960.

9 Cf. s.n.a. "Nossa directriz", Architectura no Brasil, v.1, n.1, p.1, outubro 1921. No ano anterior havia sido lançada a Revista Brasileira de Engenharia, com programa semelhante.

10 A dependência em relação ao comércio externo sediado nas cidades alimentava o pessimismo e a baixa autoestima nacional, expressos na obra de Paulo Prado (1997, p.224): "Passa pelas nossas alfândegas tudo que constitui as bençãos da civilização: [...] conhecimentos, prazeres, admirações, senso estético".

11 Cf. s.n.a. "III Congresso Pan-Americano de Architectos", Revista de Engenharia Mackenzie, v.XII, n.44, p.12, setembro 1927.

12 Cf. s.n.a. "IV Congresso Pan-Americano de architectos: Conclusões officiaes". Revista Polytechnica, v.XVII, n.100, p.283, agosto-setembro 1930.

13 Cf. ibidem, p.13.

14 Cf. s.n.a. "Movimento social - Congresso da Habitação". Boletim do Instituto de Engenharia, v.XIV, n.69, p.109, março 1931.

15 Cf. ibidem, p.14-17; s.n.a. "Congresso da Habitação". Boletim do Instituto de Engenharia, v.XIV, n.70, p.112, abril 1931.

16 Pode ser interessante assinalar a defesa de um urbanismo tradicionalista por Ricardo Severo (1917, p.418-20), ilustrada pelas realizações de Barry Parker no Porto (19151916). "O progresso do urbanismo no Brasil confirmará a these tradicionalista, no que diz respeito ao plano das cidades sobre o seu fundamento regional, os seus parques e jardins, a architectura da habitação e dos edificios publicos".

17 Quanto a Raizes do Brasil, destaca-se o capítulo final, "Nossa revolução" (Holanda, 1984, p.126-42).

18 A publicação preparada pelo MES consta de Schwartzmann (1982, p.11 e 476).

19 Em São Paulo, propostas do gênero eram entusiasticamente divulgadas por Anhaia Mello, que publicou o plano de Radburn e defendia as unidades de vizinhança e a proteção de áreas residenciais. Naquele momento (1934 a 1938), Mello ganhava influência na capital paulista, na qualidade de consultor do prefeito Fabio Prado - cuja gestão também abriu espaço a modernistas como Mário de Andrade, que passou a dirigir o novo Departamento de Cultura. 
20 Armando Augusto de Godoy, "Relatorio apresentado ao Governo do Estado de Goiaz em maio de 1937" (apud Maciel, 1996, p.649).

21 Cf. s.n.a. "Goiania e seus espaços livres”. Urbanismo e Viação, n.19, s.n.p., abril 1942.

22 As obras grandiosas do Rio foram ecoadas em Recife pela abertura da Avenida 10 de Novembro, atual Guararapes. Em São Paulo, sede de nosso maior impulso industrial, Vargas apoiou em 1938 a nomeação de Prestes Maia - em relativo ostracismo na capital desde 1930 - para implementar seu ambicioso Plano de Avenidas. Paralelamente, o Estado Novo pretendia enquadrar as massas urbanas em seu esquema conservador, transformando-as em proprietárias. A Lei do Inquilinato (1942) desestimularia a exploração dos aluguéis, enquanto a possibilidade de adquirir terrenos a prestação, aberta pelo Decreto-Lei Federal n.58, de 10 de dezembro de 1937, incentivaria a casa própria individual, considerada solução habitacional condizente com as "tradições" brasileiras.

\section{Referências}

ANDRADE, O. de. Manifesto da poesia Pau-Brasil. Correio da Manhã, Rio de Janeiro, 18 de março de 1924.

BUARQUE, S. Nossa revolução. In: __ . Raizes do Brasil. Rio de Janeiro: José Olympio, 1984. p.126-42.

DECCA, E. S. de. 1930: O silêncio dos vencidos. São Paulo: Brasiliense, 1981.

DÓRIA, C. A. O "pré-capitalismo" na formação do povo brasileiro. In: BASTOS, E. R.; MORAES, J. Q. de. (Org.) O pensamento de Oliveira Vianna. Campinas: Editora da Unicamp, 1993.

DRUMMOND, M. Momento brasileiro. A Revista, v.I, n.l e 2, p.17-18, p.44-6, 1925. FREYRE, G. Sobrados e mucambos. Rio de Janeiro: José Olympio, 1961.

GALVÃO, F. Diretrizes do Estado Novo. Rio de Janeiro: DIP, 1942.

GENTIL, A. As ideias do Presidente Getulio Vargas. Rio de Janeiro: José Olympio, 1939.

GRAÇA, A. Canã̃. Rio de Janeiro: Nova Aguilar, 1976.

GRAMSCI, A. Americanismo e fordismo. In: . Obras escolhidas. São Paulo: Martins Fontes, 1978.

IGLESIAS, F. Prefácio. In: TORRES, A. M. de S. A organização nacional. São Paulo: Cia. Editora Nacional, 1978.

MACIEL, D. P. Goiânia (1933-1963): A cidade planejada. In: Anais do IV Seminário de História da Cidade e do Urbanismo. Rio de Janeiro, 1996. p.640-3.

MELO, M. A. B. C. de. A ideologia antiurbana e a modernização da gestão municipal no Brasil: 1900-1960. In: PADILHA, N. (Org.) Cidade e urbanismo: História, teorias e práticas. Salvador: Mau/UFBA, 1998.

OLIVEIRA LIMA, M. de. Formação histórica da nacionalidade brasileira. 3.ed. Rio de Janeiro: Topbooks; São Paulo: PubliFolha, 2000.

PAIM, A. Oliveira Vianna no pensamento brasileiro. In: BASTOS, E. R.; MORAES, J. 
Q. de. (Org.) O pensamento de Oliveira Vianna. Campinas: Editora da Unicamp, 1993. p.297-310.

PRADO, P. Post scriptum (1926-1928). In: Retrato do Brasil. São Paulo: Cia. das Letras, 1997.

RIBEIRO, L. C. de Q.; CARDOSO, A. L. Da cidade à nação: gênese e evolução do urbanismo no Brasil. In: RIBEIRO, L. C. de Q.; PECHMAN, R. M. (Org.) Cidade, povo e nação: Gênese do urbanismo moderno. Rio de Janeiro: Civilização Brasileira, 1996. p.53-65.

SALIBA, E. T. Ideologia liberal e oligarquia paulista: A atuação e as ideias de Cincinato Braga. 1981. Tese (Doutorado) - Faculdade de Filosofia, Letras e Ciências Humanas, Universidade de São Paulo. São Paulo, 1981.

SARETTA, F. A política econômica na década de 20. In: DE LORENZO, H. C.; COSTA, W. P. da. (Org.) A década de 20 e as origens do Brasil moderno. São Paulo: Unesp, 1997.

SCHORSKE, C. E. A cidade segundo o pensamento europeu - de Voltaire a Spengler. Espaço \& Debates, v.IX, n.27, p.47-57, 1989.

SCHWARTZMANN, S. (Org.) Estado Novo, um auto-retrato. Brasília: UnB, 1982.

SEVCENKO, N. Orfeu extático na metrópole: São Paulo, sociedade e cultura nos frementes anos 20. São Paulo: Cia. das Letras, 1992.

Exposição universal bizarra. In:

. (Ed.) História da vida privada no Brasil.

(v.III) República: Da Belle Époque à Era do Rádio. São Paulo: Cia. das Letras, 1997a. p.106-27.

A capital irradiante: Técnicas, ritmos e ritos do Rio. In: (Ed.) História da vida privada no Brasil. (v.III) República: Da Belle Époque à Era do Rádio. São Paulo: Cia. das Letras, 1997b.

SEVERO, R. A arte tradicional no Brasil. Revista do Brasil, v.I, n.16, p.418-20, abr. 1917.

SILVA, R. C. M. da. et al. Volta Redonda e Duque de Caxias: Dois modelos urbanísticos de implantação de projetos industriais. In: Anais do IV Seminário de História da Cidade e do Urbanismo. Rio de Janeiro, 1996. p.149-50.

WILLIAM, R. O campo e a cidade na história e na literatura. São Paulo: Cia. das Letras, 1989.

RESUMO - Este trabalho aponta aspectos do debate em torno da construção da nação e da nacionalidade brasileiras, ao longo das primeiras décadas do século XX, na medida em que tais discussões envolvem temas relacionados ao urbanismo enquanto princípio e ao papel das cidades no país que se pretendia construir. Naquele momento, urbanismo se opunha a ruralismo, agrarismo e outras correntes de pensamento que viam com maus olhos os grandes centros urbanos. De maneira geral, as posições ideológicas em pauta na época debatiam-se entre termos contraditórios: de um lado, a aspiração do moderno, com suas referências urbanas, europeias e norte-americanas; de outro, a busca do caráter nacional brasileiro, em que predominariam elementos tradicionais e rurais. Urbanismo 
e antiurbanismo são elementos que podem ilustrar tais dilemas, evidenciando limites ideológicos presentes no momento da introdução da urbanística moderna no Brasil.

PALAVRAS-CHAVE: Urbanismo, Antiurbanismo, Nação, Brasil.

ABSTRACT - This study highlights aspects of the debate on the building of the Brazilian nation and nationality over the first decades of the $20^{\text {th }}$ century, to the extent that such discussions involved issues related to urban planning as a principle and to the role of cities in the country that was tentatively being built. At that time, urbanism counterposed ruralism, agrarianism and other schools of thought that took a bleak view of large urban centers. In general, the ideological positions at the time struggled between contradictory terms: on the one hand, the aspiration of modernity, with its urban, European and North American references; on the other, the pursuit of the Brazilian national character, with the predominance of traditional and rural elements. Urbanism and anti-urbanism are elements that can illustrate these dilemmas and depict the ideological limits of the introduction of modern urban planning in Brazil.

KEYWORDS: Urbanism, Anti-urbanism, Nation, Brazil.

Candido Malta Campos é arquiteto e urbanista, doutor pela FAU-USP, com pós-doutorados na New York University / Department of History e no Institut d'Urbanisme de Paris. Desde 2000 é professor do Programa de Pós-Graduação em Arquitetura e Urbanismo da Universidade Presbiteriana Mackenzie. @ - candido@mackenzie.com.br

${ }^{\text {I }}$ Faculdade de Arquitetura e Urbanismo, Universidade Presbiteriana Mackenzie, São Paulo/São Paulo, Brasil.

Recebido em 15.9.2014 e aceito em 23.10.2014. 
